\title{
Türkiye’de Arazi Toplulaştırması Üzerine Yapılmış Akademik Çalışmaların Analizi
}

\author{
Tahsin BOZTOPRAK ${ }^{1 *}$, Osman DEMIR ${ }^{2}$, Yakup Emre ÇORUHLU ${ }^{2}$ \\ ${ }^{1}$ Devlet Su Isşleri 12. Bölge Müdürlüğü Emlak ve Kamulaştırma Şube Müdürlüğü, Kayseri \\ ${ }^{2}$ Karadeniz Teknik Üniversitesi Mühendislik Fakültesi Harita Mühendisliği Bölümü, Trabzon
}

Geliş (Received): 11.07.2015

Kabul (Accepted): 31.12.2015

\begin{abstract}
ÖZET: Bu çalışmanın amacı; arazi toplulaştırması konusunda yapılan akademik çalışmaların genel eğilimlerini ortaya çıkarmak ve bu konuda araştırma yapmayı düşünen araştırmacıların çalışmalarına 1şık tutmaktır. Bu amaç doğrultusunda, 2000-2015 yılları arasında yayımlanan 92 akademik çalışma, içerik analiz yöntemiyle incelenmiştir. 92 akademik çalışmanın 11'i doktora tezi, 35'i yüksek lisans tezi ve 46'sı ulusal ve uluslararası dergilerde yayınlanan makalelerden oluşmaktadır. İçerik analiz yöntemiyle yayınların yıllara göre dağılımı, üniversitelere göre dağılımı, araştırmacıların mesleklerine göre dağılımı ve yayınların hangi konuları içerdiği incelenerek sınıflandırılmıştır. Sonuç olarak en fazla araştırılan konuların arazi toplulaştırmasının arazi parçalılığına, parsel sayısına ve ortalama parsel büyüklüğüne etkisi olduğu belirlenmiştir. Ayrıca ziraat mühendisi araştırmacılarının harita mühendisi araştırmacılarına göre daha fazla yayın yaptığı da belirlenmiştir.
\end{abstract}

Anahtar Kelimeler: Arazi Toplulaştırması, İçerik analizi, Lisansüstü tez, Makale

\section{Analysis of the Academic Study on the Land Consolidation in Turkey}

ABSTRACT: The aim of this study is to find out the main tendencies of academic studies on land consolidation and it is supposed to shed light on studies of researchers who think about studying on this field. To accomplish this purpose, 92 academic studies published between 2000 and 2015 were examined by using content analysis method. These 92 academic studies are composed of 11 phd thesis, 35 master thesis and 46 articles, published on national/international magazines, all of these were prepared by Turkish researchers. With the help of content analysis method, distribution of issues by years, university, occupation of the researchers and topics was examined and categorized. As a conclusion, it was found out that effects of land consodilation on fragmentation of land, the number of parcels and average parcel size were the most investigated subjects. In addition to this it was determined that agricultural engineers who are researchers produced publications more than geomatic engineers as researchers.

Key Words: Land consolidation, content analysis, paper, master and phd

\section{GİRIŞ}

Bilimsel araştırmalar, bilim ve teknoloji alanının ve toplumun gelişmesinin en dinamik unsurunu oluştururlar. Herhangi bir bilim dalında gerçekleştirilmiş olan yazılı çalışmaların belirli dönemler itibariyle incelenmesi hem ele alınan bilim dalındaki gelişim düzeyinin belirlenmesi hem de ağırlıklı olarak hangi konular üzerinde yoğunluk olduğunun belirlenmesi açısından büyük önem arz etmektedir. $\mathrm{Bu}$ tür çalışmalar sonucu elde edilen bulgular bir taraftan incelemeye konu olan bilim dalının zaman içerisinde gösterdiği gelişimin takibini kolaylaştırmakta, bir taraftan da, o konunun derinliği ve yaygınlığ 1 hakkında bilgiler verirken genel görünümünü de ortaya çıkarmaktadır (Kozak ve Çiçek, 2012; Kozak, 2000; Alkan, 2014; Turan ve ark., 2014).

Planlanan her yeni araştırma daha önce yapılmış çalışmaların derinlemesine incelenmesi ile ortaya çıkar ve zamanla nitelik kazanır. Alanda yapılan çalışmalar hakkında bilgi vermek araştırmacılara büyük kolaylık ve imkân sağlar. Yapılan çalışmaların sistematik analizleri, çalışma yapacaklara o alanda nelerin yapıldığını veya yapılmadığını göstererek rehberlik eder. Akademik ortamdaki bu yayınlar, çalışma sonuçlarının daha net bir şekilde görülmesini ve değerlendirilmesini sağlayarak büyük bir destek sağlar. Ayrıca içerik analizi çalışmaları alandaki boşlukları ve eksikleri göstermenin yanında yapılan çalıșmaların niteliklerinin değerlendirilmesi ve kullanılabilirliği açısından da büyük katkılar sağlayacaktır (Kanlı ve ark., 2014).

Bir alanda yapılmış olan çalışmaların belirli aralıklarla incelenmesi türündeki içerik çalıșmaları sosyal bilimlerde yaygın olarak kullanılmak birlikte, fen bilimlerinde çok rastlanılan bir çalışma türü değildir.

Ülkemizde arazi toplulaştırması konusu ile ilgili daha önce üretilen güncel yayınlar, arazi toplulaştırma projelerinde meydana gelen bir takım sorunların sistematikleşebileceğini göstermiştir. Özellikle farklı bölgelerde, farklı ölçeklerde ve farklı mevzuatlara göre yapılan çalışmalarda dahi benzer sonuçlar ortaya çıkmaktadır (Boztoprak vd., 2015a). Farklı disiplinlerce yürütülmüş bu tip çalışmaların bütününü birden ele alarak değerlendiren bir çalışma literatürde genel hatları ile yer etmemiştir. Yani arazi toplulaştırması konusunda ki mevcut durum, sorun ve çözüm önerilerine daha önce üretilmiş çalışmaların büyük bir bölümünün analizi ile farklı bir açıdan nasıl bakılabilir sorusu yanıtlanmaya çalışılmamıştır.

$\mathrm{Bu}$ çalışmada, arazi toplulaştırma konusu üzerine ülkemizde 2000-2015 yılları arasında yayınlanmış yüksek lisans ve doktora tezleri ile Türk araştırmacılar 
tarafindan ulusal ve uluslararası dergilerde yayınlanan makalelerin içerik analiz çalışması yapılmıştır.

\section{MATERYAL VE YÖNTEM}

\section{Araştırmanın Modeli}

$\mathrm{Bu}$ araştırmada; Türkiye'de arazi toplulaştırma konusunda 2000-2015 yılları arasında ülkemizde yapılmış yüksek lisans ve doktora tezleri ile Türk araştırmacılar tarafindan ulusal ve uluslararası dergilerde yayınlanan makalelerin tematik dağılımlarını ortaya koymaktadır. $\mathrm{Bu}$ nedenle araştırma betimsel nitelikte olup, tarama modeli tipindedir.

\section{Evren ve Örneklem}

Araştırmada, Türkiye'de arazi toplulaştırma konusunun tematik olarak durumunun belirlenmesi çalışılmıştır. Araştırmanın kuramsal evreni Yüksek Öğretim Kurulu Ulusal Tez Merkezinde (http://tez2.yok.gov.tr) dizgilenen yüksek lisans ve doktora tezleri ile Türk araştırmacılar tarafından ulusal ve uluslararası dergilerden yayınlanan makalelerden oluşmaktadır.

Araştırmanın örneklemi ise arazi toplulaştırması (arazi toplulaştırmasi, toplulaştırma ve arazi düzenlemesi) konusunda Yüksek Öğretim Kurulu Ulusal Tez Merkezinde 2000-2015 yılları arasinda yayınlanan 11 adet doktora tezi ve 35 adet yüksek lisans tezi olmak üzere toplam 46 lisansüstü tez ile Türk araştırmacılar tarafindan ulusal ve uluslararası dergilerden yayınlanan 46 adet makaleden oluşmaktadır.

\section{Verilerin Toplanmas}

Araştırmada verilerin toplanması iki aşamada gerçekleşmiştir. Birinci aşamasında, örneklem grubunda yer alan yüksek lisans ve doktora tezleri Yükseköğretim Kurulu Ulusal Tez Merkezi resmi sitesinden bilgisayar ortamına aktarılmıştır. İkinci aşamada ise, arazi toplulaştırması konusunda Türk araştırmacılar tarafindan ulusal ve uluslararası dergilerde yayınlanan makaleler internette taratılarak bilgisayar ortamina aktarılmıştır.

\section{Verilerin Analizi}

Çalışmadan elde edilen veriler; nitel araştırmalarda kullanılan analiz türlerinden içerik analizi ile elde edilmiştir. İçerik analizi; doğrudan ölçülemeyen ve gözlemlenemeyen çalışmalarda kullanılan, bir mesajın belirli ve açıkça ifade edilmiş özelliklerini objektif ve sistematik bir biçimde saptamamızı ve bunlar hakkında çıkarım yapmamızı sağlayan bir yöntemdir. $\mathrm{Bu}$ yöntem araştırmacılara, alandaki araştırmaların eğilimlerini ve ilgi alanlarını görmelerini sağladığı için onlara daha yararlı araştırmalar yapmaları konusunda yol göstericilik eder (Doğru ve ark., 2012).

Bu çalışmada, veriler analiz edilirken; yüksek lisans ve doktora tezlerinden "kısitlaması olmayan tezler" ile makaleler detaylı bir şekilde analiz edilmiştir. "Kısıtlaması olan tezler" ise özetlerinde verilen bilgiler doğrultusunda analiz edilmiştir. Yayınların yılı, araştırmacının branşı, araştırmacının çalıştığ kurum, araştırmada incelenen konular alt başlıklara göre analiz edilmiş ve ilgili tablolarda sunulmuştur.

\section{BULGULAR}

\section{Lisansüstü Tezlere İlişkin Bulgular}

Ülkemizde 2000-2015 yılları arasında YÖK Ulusal Tez Merkezi resmi web sitesinde arazi toplulaştırması konusunda dizgilenen 11 adet (\%23.91) doktora tezi ve 35 adet (\%76.09) yüksek lisans tezi olmak üzere toplam 46 adet lisansüstü tez yayınlamıştır.

Şekil 1, 2000-2015 yılları arasında arazi toplulaştırması üzerine ülkemizde yayınlanan tezlerin yıllara göre dağılımını yansitmaktadır. Şekil incelendiğinde 2010 yılında 6 adet (\%13.04), 2012 ve 2014 y1llarında 5 adet (\%10.87), 2001, 2002 ve 2004 yıllarında 4 adet $(\% 8.70)$ lisansüstü tezin yayınlandığ görülmektedir. 2003, 2007, 2008, 2013 ve 2015 (Ilk yarıs1) yıllarında doktora, 2011 yılında yüksek lisans tezi yayınlanmadığı görülmektedir.

Çizelge 1, arazi toplulaştırması konusu ile ilgili yayınlanan lisansüstü tezlerin üniversitelere göre dağılımını sunmaktadır. Çizelge 1 incelendiğinde, bu araştırmada analiz edilen 46 adet lisansüstü tezin on dokuz (19) farklı devlet üniversitesinde yürütüldüğü görülmektedir. Lisansüstü tezlerin ağırlıklı olarak da Selçuk Üniversitesi (\% 26.08), Ankara Üniversitesi (\%13.04) ve Uludağ Üniversitesinde (\%13.04) gerçekleştirildiği görülmektedir. Ayrıca herhangi bir özel üniversitede arazi toplulaştırması ile ilgili bir tez çalışması yapılmamıştır.

Yayınlanan lisansüstü tezlerin 33'ü (\%71.74) Ziraat Mühendisliği, 11'i (\%23.91) Harita Mühendisliği Anabilim Dalında hazırlanan tezlerdir. 


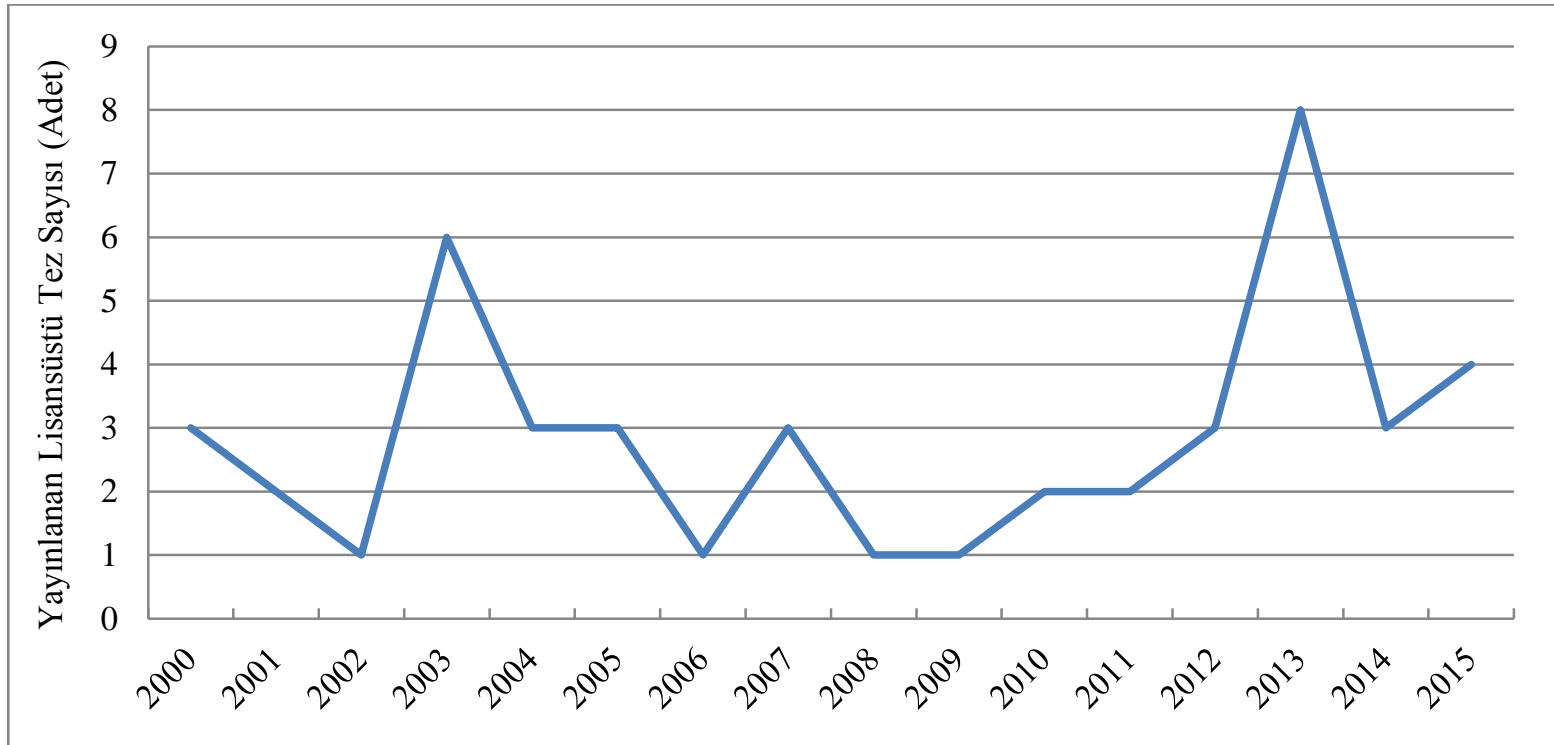

Şekil 1. Yayınlanan Lisansüstü Tezlerin Yıllara Göre Dağıılımı

Çizelge 1. Yayınlanan Lisansüstü Tezlerin Üniversitelere Göre Dağılımı

\begin{tabular}{|c|c|c|c|c|c|c|c|}
\hline \multirow[b]{2}{*}{ Üniversite } & \multirow[b]{2}{*}{ Anabilim Dalı } & \multicolumn{2}{|c|}{ Doktora } & \multicolumn{2}{|c|}{ Yüksek Lisans } & \multicolumn{2}{|c|}{ Toplam } \\
\hline & & $\begin{array}{l}\text { Yayın } \\
\text { (Adet) }\end{array}$ & $\begin{array}{c}\text { Oran } \\
(\%)\end{array}$ & $\begin{array}{l}\text { Yayın } \\
\text { (Adet) }\end{array}$ & $\begin{array}{l}\text { Oran } \\
(\%)\end{array}$ & $\begin{array}{l}\text { Yayın } \\
\text { (Adet) }\end{array}$ & $\begin{array}{l}\text { Oran } \\
(\%)\end{array}$ \\
\hline Adnan Menderes & Ziraat & & & 1 & 2.86 & 1 & 2.17 \\
\hline Aksaray & Harita & & & 1 & 2.86 & 1 & 2.17 \\
\hline Ankara & Ziraat & 2 & 18.18 & 4 & 11.43 & 6 & 13.04 \\
\hline Atatürk & Ziraat & 1 & 9.09 & 1 & 2.86 & 2 & 4.35 \\
\hline Çanakkale Onsekiz & Ziraat & & & 2 & 5.71 & 2 & 4.35 \\
\hline Çukurova & Peyzaj Mimarlığ & & & 1 & 2.86 & 1 & 2.17 \\
\hline Ege & Ziraat & & & 1 & 2.86 & 1 & 2.17 \\
\hline Erciyes & Harita & & & 1 & 2.86 & 1 & 2.17 \\
\hline Gazi & Şehir ve Böl. & & & 1 & 2.86 & 1 & 2.17 \\
\hline Gaziosmanpaşa & Ziraat & 1 & 9.09 & 2 & 5.71 & 3 & 6.52 \\
\hline İstanbul Teknik & Harita & & & 1 & 2.86 & 1 & 2.17 \\
\hline K. Sütçü İmam & Ziraat & & & 2 & 5.71 & 2 & 4.35 \\
\hline Karadeniz Teknik & Harita & & & 1 & 2.86 & 1 & 2.17 \\
\hline Namık Kemal & Ziraat & & & 1 & 2.86 & 1 & 2.17 \\
\hline Ondokuz Mayis & Ziraat & & & 1 & 2.86 & 1 & 2.17 \\
\hline Selçuk & Harita & 3 & 27.27 & 3 & 8.57 & 6 & 13.04 \\
\hline Selçuk & Ziraat & 2 & 18.18 & 4 & 11.43 & 6 & 13.04 \\
\hline Trakya & Ziraat & & & 2 & 5.71 & 2 & 4.35 \\
\hline Uludağ & Ziraat & 2 & 18.18 & 4 & 11.43 & 6 & 13.04 \\
\hline Yildız Teknik & Harita & & & 1 & 2.86 & 1 & 2.17 \\
\hline Toplam & & 11 & 23.91 & 35 & 76.09 & 46 & 100.00 \\
\hline
\end{tabular}

Çizelge 2, arazi toplulaştırması konusu ile ilgili yayınlanan lisansüstü tezlerde araştırılan konuların dağılımı gösterilmektedir. Çizelge 2'ye göre, arazi toplulaştırması ile ilgili toplamda on iki (12) farklı konuda çalışma gerçekleştirilmiştir. En fazla çalışmanın yapıldığı konular sırasıyla şunlardır: (i) arazi toplulaştırmasının parsel sayısına etkisi/arazi parçalılığ (\%65.22), (ii) arazi toplulaştırmasının ortalama parsel büyüklüğüne etkisi $(\% 58.70)$ ve (iii) arazi toplulaştırmasının tarımsal altyapı/sulamaya etkisi (\%50.00). En az çalışmanın yapıldığı konular ise şunlardır: (i) arazi toplulaştırmasında kullanılan derecelendirme/değerleme/toprak analizi (\%6.52), (ii) arazi toplulaştırma hakkında genel bilgi/değerlendirme/mevzuat (\%10.87) ve (iii) arazi toplulaştırmasının çevresel etkileri/kamulaştırmaya etkisi (\%13.04). Arazi toplulaştırmasının en önemli amacı olan parsel sayısını azaltmak ve ortalama parsel büyüklüğünü artırmak olduğu için araştırmacıların bu konulara ağırlık vermesi makul karşılanabilir. Ancak arazi toplulaştırması için hayati öneme sahip derecelendirme konusunda daha fazla çalışmaya ihtiyaç duyulduğunu göstermektedir. 
Çizelge 2. Lisansüstü Tezlerde İncelenen Konulara Göre Dağılım

\begin{tabular}{|c|c|c|c|c|c|c|c|c|c|c|c|c|c|}
\hline 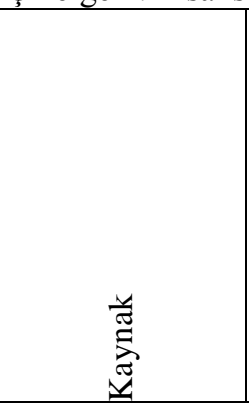 & 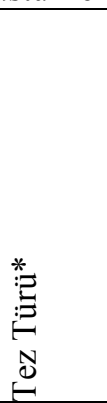 & 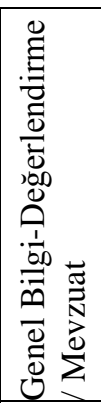 & 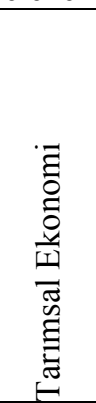 & 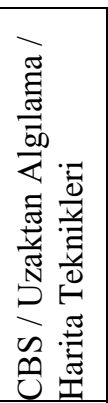 & 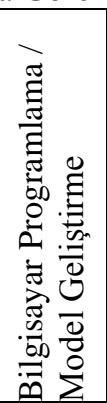 & 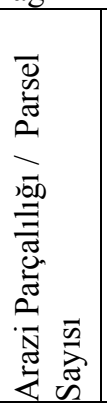 & 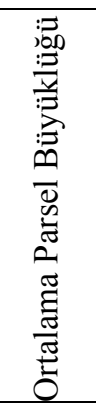 & 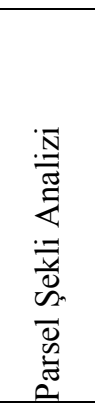 & 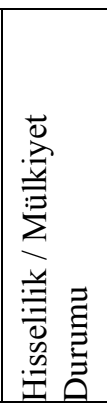 & 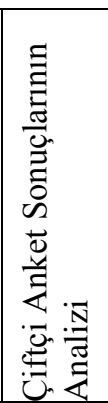 & 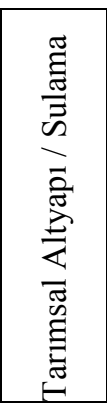 & 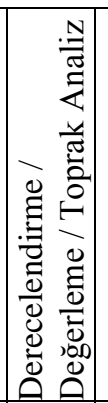 & 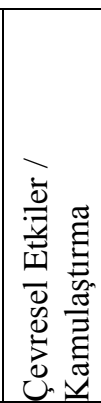 \\
\hline Çelik, 2000 & Dr & & & & & & & & & & & & \\
\hline Uçar, 2001 & Dr & & & & & & & & & & & & \\
\hline Akkaya Aslan, 2002 & Dr & & & & & & & & & & & & \\
\hline Akkaya, 2004 & Dr & & & & & & & & & & & & \\
\hline Kuşlu, 2004 & Dr & & & & & & & & & & & & \\
\hline Altıntaş, 2006 & Dr & & & & & & & & & & & & \\
\hline İşcan, 2009 & Dr & & & & & & & & & & & & \\
\hline Kirmikil, 2010 & Dr & & & & & & & & & & & & \\
\hline Uyan, 2011 & $\mathrm{Y} 1$ & & & & & & & & & & & & \\
\hline Dinçbilek, 2012 & $\mathrm{Y} 1$ & & & & & & & & & & & & \\
\hline İnceyol, 2014 & $\mathrm{Y} 1$ & & & & & & & & & & & & \\
\hline Erdoğan,2000 & $\mathrm{Y} 1$ & & & & & & & & & & & & \\
\hline İnceyol,2000 & $\mathrm{Y} 1$ & & & & & & & & & & & & \\
\hline Ünal,2001 & $\mathrm{Yl}$ & & & & & & & & & & & & \\
\hline Şahin,2001 & $\mathrm{Y} 1$ & & & & & & & & & & & & \\
\hline Y1lmaz, 2001 & $\mathrm{Y} 1$ & & & & & & & & & & & & \\
\hline Uzun,2002 & $\mathrm{Yl}$ & & & & & & & & & & & & \\
\hline Uçar,2002 & Y1 & & & & & & & & & & & & \\
\hline Köseoğlu,2002 & $\mathrm{Y} 1$ & & & & & & & & & & & & \\
\hline İşcan,2003 & $\mathrm{Y} 1$ & & & & & & & & & & & & \\
\hline Ünal,2003 & $\mathrm{Y} 1$ & & & & & & & & & & & & \\
\hline Önal,2004 & $\mathrm{Y} 1$ & & & & & & & & & & & & \\
\hline Göçmen,2004 & $\mathrm{Y} 1$ & & & & & & & & & & & & \\
\hline Durukan,2005 & $\mathrm{Y} 1$ & & & & & & & & & & & & \\
\hline Sert,2005 & $\mathrm{Y} 1$ & & & & & & & & & & & & \\
\hline Eser,2006 & $\mathrm{Yl}$ & & & & & & & & & & & & \\
\hline Bursalı,2007 & $\mathrm{Yl}$ & & & & & & & & & & & & \\
\hline Küzeci,2008 & $\mathrm{Y} 1$ & & & & & & & & & & & & \\
\hline Güler,2010 & $\mathrm{Y} 1$ & & & & & & & & & & & & \\
\hline Kızılok,2009 & $\mathrm{Y} 1$ & & & & & & & & & & & & \\
\hline Köse,2009 & $\mathrm{Y} 1$ & & & & & & & & & & & & \\
\hline Çevik, 2010 & $\mathrm{Yl}$ & & & & & & & & & & & & \\
\hline Boztoprak,2010 & $\mathrm{Y1}$ & & & & & & & & & & & & \\
\hline Ekinci,2010 & $\mathrm{Y} 1$ & & & & & & & & & & & & \\
\hline Özer,2010 & $\mathrm{Y} 1$ & & & & & & & & & & & & \\
\hline Kara,2012 & $\mathrm{Yl}$ & & & & & & & & & & & & \\
\hline Sönmezylldı,2012 & $\mathrm{Y} 1$ & & & & & & & & & & & & \\
\hline Kur,2012 & $\mathrm{Y} 1$ & & & & & & & & & & & & \\
\hline Manavbaşı,2012 & $\mathrm{Y} 1$ & & & & & & & & & & & & \\
\hline Temel,2013 & $\mathrm{Y} 1$ & & & & & & & & & & & & \\
\hline Itır,2013 & $\mathrm{Yl}$ & & & & & & & & & & & & \\
\hline Bilgin,2014 & $\mathrm{Y} 1$ & & & & & & & & & & & & \\
\hline Tuşat,2014 & $\mathrm{Y} 1$ & & & & & & & & & & & & \\
\hline Keskin,2014 & $\mathrm{Y} 1$ & & & & & & & & & & & & \\
\hline Ünal Akyürek,2014 & $\mathrm{Y} 1$ & & & & & & & & & & & & \\
\hline Ormanc1,2015 & $\mathrm{Y} 1$ & & & & & & & & & & & & \\
\hline Toplam & 46 & 5 & 11 & 6 & 8 & 30 & 27 & 17 & 10 & 13 & 23 & 3 & 6 \\
\hline Oran $(\%)$ & 100.00 & 10.87 & 23.91 & 13.04 & 17.39 & 65.22 & 58.70 & 36.96 & 21.74 & 28.26 & 50.00 & 6.52 & 13.04 \\
\hline
\end{tabular}

* Doktora tezleri Dr, yüksek lisans tezleri Yl ile ifade edilmiştir. 
Lisansüstü tezlerde incelenen on iki farklı konudan, 13 tez bir konuyu, 2 tez iki konuyu, 7 tez üç konuyu, 8 tez dört konuyu, 9 tez beş konuyu, 6 tez altı konuyu ve 1 tez sekiz konuyu araştırmıştır (Çizelge 2).

\section{Akademik Makalelere İlişkin Bulgular}

Şekil 2, 2000-2015 yılları arasında arazi toplulaştırması üzerine Türk araştırmacılarının ulusal ve uluslararası dergilerde yayınlanan akademik makalelerinin yıllara göre dağılımını yansıtmaktadır. Şekil 2 incelendiğinde en fazla akademik makalenin 2013 yllinda 7 adet $(\% 15.22)$ ve 2003 y1linda 6 adet (\%13.04) yayınlandığı görülmektedir. En az akademik makale 1 adet (\%2.17) ile 2002, 2006, 2008 ve 2009 yıllarında yayınlanmıştır.

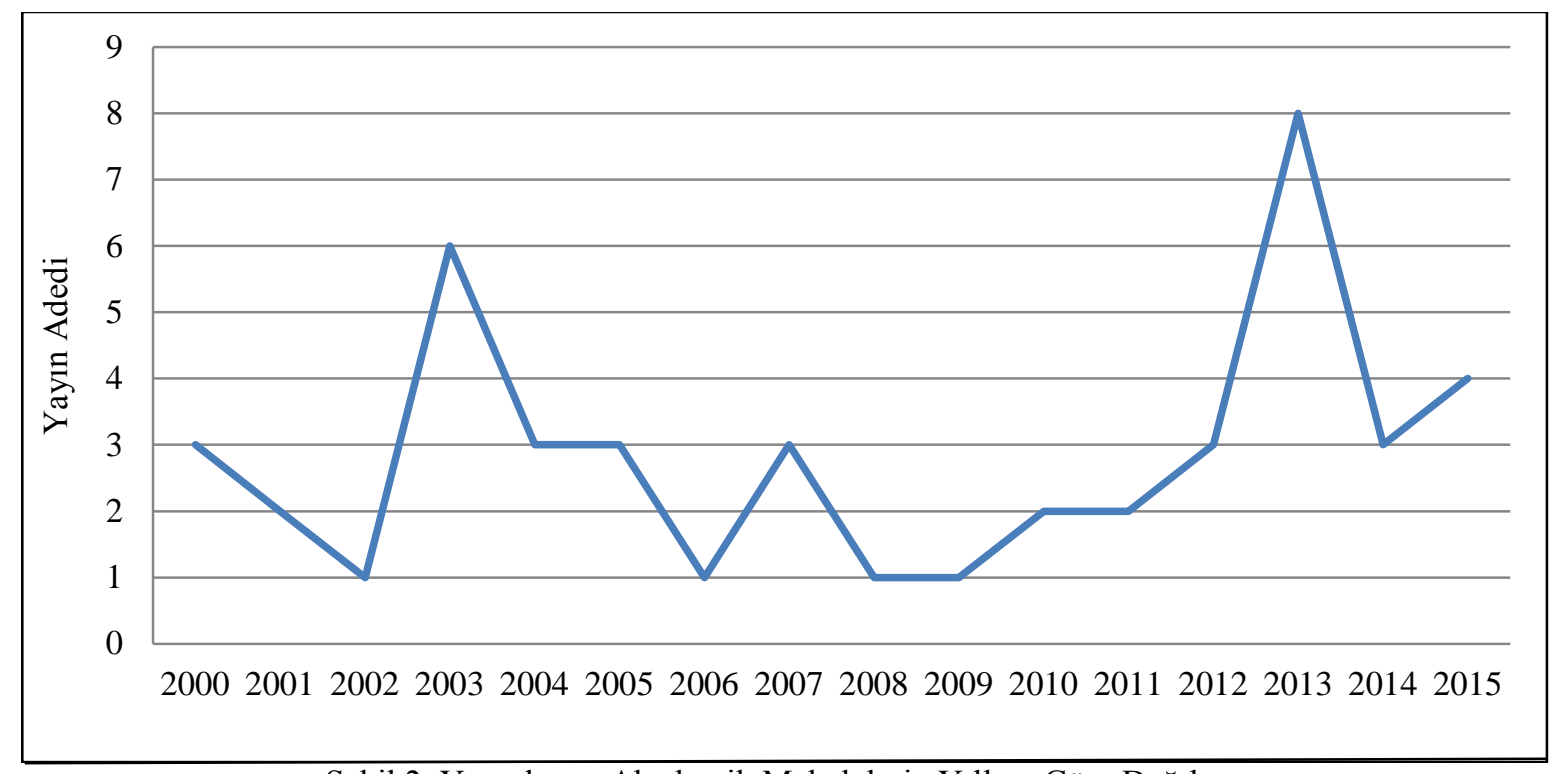

Şekil 2. Yayınlanan Akademik Makalelerin Yıllara Göre Dağılımı

Çizelge 3, arazi toplulaştırması konusunda yayınlanan makalelerin yazar sayısını göstermektedir. Çizelge 3'e göre, arazi toplulaştırması ile ilgili makalelerin yazar sayısı 1 ile 5 arasında değişmekte olup iki isimli makaleler çoğunluktadır. Bu durum, arazi toplulaştırması ile ilgili makalelerin genellikle çok yazarlı olarak gerçekleştirildiğinin bir göstergesi sayılabilir.

Çizelge 3. İncelenen Akademik Makalelerdeki Yazar Say1s1

\begin{tabular}{ccr}
\hline Yazar Say1s1 & Makale Say1s1 & Oran1 (\%) \\
\hline 1 & 12 & 26.09 \\
\hline 2 & 22 & 47.83 \\
\hline 3 & 6 & 13.04 \\
\hline 4 & 5 & 10.87 \\
\hline 5 & 1 & 2.17 \\
\hline Toplam & 46 & 100.00 \\
\hline
\end{tabular}

Çizelge 4, arazi toplulaştırması konusu ile ilgili yayınlanan akademik makalelerde ismi bulunana araştırmacıların makale sayılarına ilişkin dağılım gösterilmektedir.

Çizelge 4'e göre akademik makalelerde ismi bir kere geçen araştırmacı sayısı 49 (\%72.06), iki defa geçen araştırmacı sayısı 12 (\%17.65) olduğu görülmektedir. Ayrıca üc ve üzere yayında ismi geçen araștırmacı sayısının çok az olduğu görülmektedir.
Çizelge 4. Akademik Makalelerde İsmi Geçen Yazarların Makale Sayısı

\begin{tabular}{ccr}
\hline Yazar Ad1 Sayıs1 & Makale Sayısı & Oranı (\%) \\
\hline 1 & 49 & 72.06 \\
\hline 2 & 12 & 17.65 \\
\hline 3 & 4 & 5.88 \\
\hline 4 & 1 & 1.47 \\
\hline 5 & 1 & 1.47 \\
\hline 6 & 1 & 1.47 \\
\hline Toplam & 68 & 100.00 \\
\hline
\end{tabular}

Çizelge 5, arazi toplulaştırması konusu ile ilgili yayınlanan akademik makalelerde araştırılan konuların dağıllımı gösterilmektedir.

Çizelge 5'e göre akademik makalelerin \%10'u (\%21.74) lisansüstü tezlerden üretilmiștir. En fazla çalıșmanın yapıldı ğı konular sırasıyla șunlardır: (i) arazi toplulaştırmasının parsel sayısına etkisi/arazi parçalılığ (\%34.78), (ii) arazi toplulaştırmasının ortalama parsel büyüklüğüne etkisi (\% 32.61) ve (iii) arazi toplulaștırma hakkında genel bilgi/değerlendirme/mevzuat (\%26.09). En az çalışmanın yapıldı ğı konular ise șunlardır: (i) arazi toplulaştırmasının çevreye etkisi/kamulaştırma ile arazi toplulaştırmasının mülkiyet durumuna etkisi/hisselilik durumu analizi (\%6.52) ve (ii) arazi toplulaştırmasında kullanilan derecelendirme/değerleme/toprak analizi (\% 8.70). 
Çizelge 5. Araştırma Kapsamında İncelenen Makalelere Ait Bilgiler

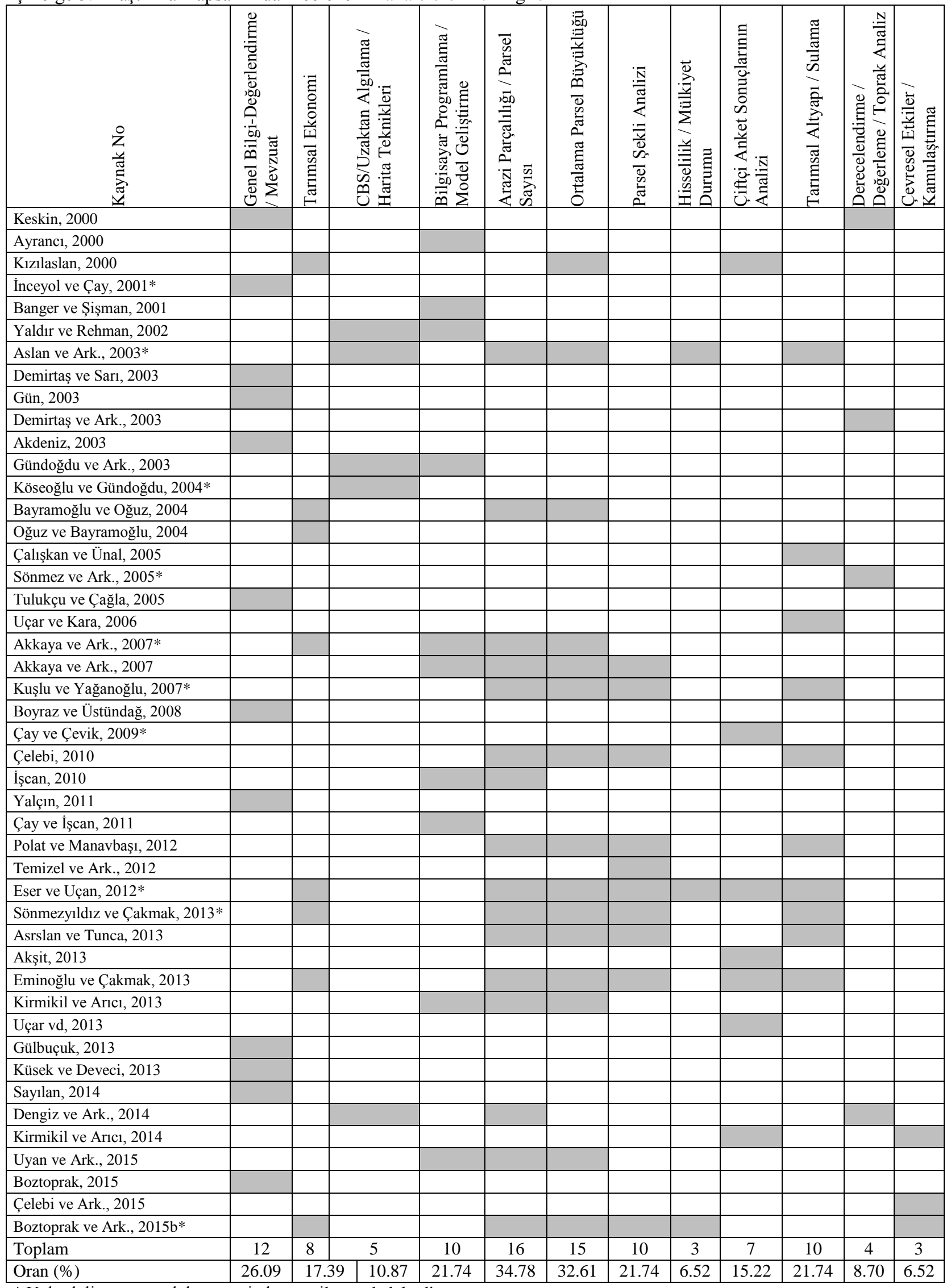

* Yüksek lisans veya doktora tezinden üretilen makalelerdir. 
Akademik makalelerde araştırılan konular, lisansüstü tezlerde araştırılan konulara paralellik göstermektedir. Ancak arazi toplulaştırma hakkında genel bilgi/değerlendirme/mevzuat konusu tezlerde en az araştırılan konu iken, akademik makalelerde en fazla araştırılan konulardan birisi olmuştur.

Akademik makalelerde incelenen on iki farkl1 konudan, 25 makale bir konuyu, 5 makale iki konuyu,5 makale üç konuyu, 6 makale dört konuyu, 2 makale beş konuyu, 2 makale altı konuyu ve 1 makale yedi konuyu araştırmıştır (Çizelge 5).

\section{Araştırmacılara İlişkin Bulgular}

Çizelge 6, arazi toplulaştırması konusu ile ilgili yayınlanan lisansüstü tezlerde ve akademik makalelerde ismi geçen araştırmacıların çalıștıkları sektörlere göre dağılımı gösterilmektedir. Arazi toplulaştırması konusunda yayınlanan lisansüstü tezlerde ve akademik makalelerde toplam 96 araştırmacının ismi geçmektedir. Bilimsel yayınları hazırlayan araştırmacıların 31 'i (\%32.29) özel/kamu sektöründe görevli iken, 65 (\%67.71) araştırmacı çeşitli üniversitelerde görev yapmaktadir.

Ülkemizde arazi toplulaştırması uygulamasını ağırlıklı olarak iki mühendislik dalı gerçekleștirmektedir. Bunlar Harita ve Kadastro Mühendisliği ile Ziraat Mühendisliğidir (Akdeniz, 2008). Araştırmacıların 7'si (\%7.29) Özel/Kamu sektöründe, 15 'i üniversitede görevli olmak üzere toplam 22'si (\%22.92) Harita Mühendisi, 21'i (\%21.88) Özel/Kamu sektöründe, 48’i (\%50.00) üniversitede görevli olmak üzere toplam 69'u (\%71.88) Ziraat Mühendisidir.

Çizelge 6. Araştırmacıların Çalıştıkları Sektöre Göre Dağılımı

\begin{tabular}{lcccccc}
\hline & Özel/Kamu Sektörü & \multicolumn{2}{c}{ Üniversite } & \multicolumn{2}{c}{ Toplam } \\
\hline Araștırmacı Branșı & Araștırmac1 & Oran1 & Araștırmac1 & Oran1 & Araştırmac1 & Oranı \\
\hline Harita & 7 & 7.29 & 15 & 15.63 & 22 & 22.92 \\
\hline Ziraat & 21 & 21.88 & 48 & 50.00 & 69 & 71.88 \\
\hline Çevre & 1 & 1.04 & - & 0.00 & 1 & 1.04 \\
\hline Peyzaj Mimarı & 1 & 1.04 & - & 0.00 & 1 & 1.04 \\
\hline Șehircilik ve Bölge & 1 & 1.04 & - & 0.00 & 1 & 1.04 \\
\hline Bilgisayar & - & 0.00 & 1 & 1.04 & 1 & 1.04 \\
\hline Eğitim & - & 0.00 & 1 & 1.04 & 1 & 1.04 \\
\hline Toplam & 31 & 32.29 & 65 & 67.71 & 96 & 100.00 \\
\hline
\end{tabular}

Çizelge 7, arazi toplulaștırması konusu ile ilgili yayınlanan lisansüstü tezlerde ve akademik makalelerde ismi geçen ve çeşitli üniversitelerde görevli olan araştırmacıların, görevli oldukları üniversitelere göre dağılımı gösterilmektedir

Çizelge 7. Üniversiteli Araştırmacıların Görevli Oldukları Üniversitelere Göre Dağılımı

\begin{tabular}{llr}
\hline Üniversite & Araştırmac1 Sayısı & Oran \\
\hline Selçuk & 15 & 23,08 \\
\hline Ankara & 12 & 18,46 \\
\hline Ondokuzmayıs & 8 & 12,31 \\
\hline Uludă̆ & 8 & 12,31 \\
\hline Akdeniz & 3 & 4,62 \\
\hline Karadeniz Teknik & 3 & 4,62 \\
\hline Ege & 2 & 3,08 \\
\hline Frrat & 2 & 3,08 \\
\hline GOP & 2 & 3,08 \\
\hline Adıyaman & 1 & 1,54 \\
\hline Atatürk & 1 & 1,54 \\
\hline Erciyes & 1 & 1,54 \\
\hline Harran & 1 & 1,54 \\
\hline Kahramanmaraş & 1 & 1,54 \\
\hline Muğla & 1 & 1,54 \\
\hline Osmaniye Korkut & 1 & 1,54 \\
\hline Pamukkale & 1 & 1,54 \\
\hline Süleyman Demirel & 1 & 1,54 \\
\hline Yüzüncü Y1l & 1 & 1,54 \\
\hline Toplam & 65 & 100.00 \\
\hline
\end{tabular}

Üniversiteli araştırmacıların 15'i (\% 23.08) Selçuk Üniversitesi'nde görevli iken, 12 (\% 18.46) araştırmacı Ankara Üniversitesinde 8'er (\% 12.31) araştırmac1 Ondokuzmayıs Üniversitesi ve Uludağ Üniversitesinde görev yapmaktadır (Çizelge 2).

\section{SONUÇ ve ÖNERÍLER}

1961 yılında Konya-Çumra'da uygulanmaya başlanan arazi toplulaştırması projeleri son yıllarda yaygınlaşmaya başlanmıştır. $\mathrm{Bu}$ yaygınlaşmaya paralel olarak daha fazla akademik çalışmaya konu olmaktadır. Çalışma kapsamında 2000-2015 yılları arasında arazi toplulaştırması konusunda yayınlanmış 92 akademik çalışma incelenmiştir.

Yapılan araştırmalar incelendiğinde Ziraat Mühendisliğine ait yayınların Harita Mühendisine ait yayınlardan çok daha fazla olduğu görülmektedir. Bunun nedeni uygulama sonrasında yapılan çalıșmaların genellikle Ziraat Mühendisliği branşları ile ilgili olmasından kaynaklandığı düşünülmektedir. Bu nedenle Harita Mühendisi araştırmacılarının arazi toplulaştırması konusunda daha fazla yayın yapması, arazi toplulaştırma projesinde çalışan/çalışacak Harita Mühendislerine çalışmalarında yön vermesi açısından önemli fayda sağlayacağı düşünülmektedir.

Üniversitelerin tez yayınları incelediğinde, en fazla Ankara, Uludağ ve Selçuk Üniversitelerinden tez yayınlandığ1 görülmektedir. Üniversite bünyesinde Ziraat Mühendisliği veya Harita Mühendisliği bölümü 
bulunan üniversiteler, arazi toplulaştırması konusunda daha fazla yayın yapması önerilmektedir.

\section{KAYNAKLAR}

Akdeniz, H. 2003. Tarım Kesininin Kalkınmasında Bir Çözüm Olarak Arazı Toplulaştırması. Amme İdaresi Dergisi, 36 (4): 127-151.

Akdeniz, H. 2008. Toprak Koruma, Arazi Kullanımı ve Toplulaştırma, 2. Kadastro Kongresi, 21-24 Mayıs 2008, DSİ Konferans Salonu, Ankara.

Akkaya Aslan Ş.T., Arıcı İ. 2003. Bursa Karacabey Projesi Planlama Bilgilerinin ARTOP Arazi Toplulaştırma Bilgi Sistemi ile Analizi. Uludağ Üniversitesi Ziraat Fakültesi Dergisi, 17 (2): 111 124.

Akkaya, Aslan, Ș.T. 2002. Arazi Toplulaştırmasında CBS Destekli Planlama Bilgi Sisteminin Geliştirilmesi ve Planlama Verilerinin Analizi. Uludağ Üniversitesi Fen Bilimleri Enstitüsü Tarımsal Yapılar ve Sulama Anabilim Dalı, Doktora Tezi, Bursa.

Akkaya Aslan, Ş.T., Gündoğdu, K.S., M., Arıcı, İ. 2007. Some Metric Indices for the Assessment of Land Consolidation, Projects. Pakistan Journal of Biological Sciences, 10(9):1390-1397.

Akkaya Aslan, Ş.T., Gündoğdu, K.S., Yaslıoğlu, E., Kirmikil, M., Arıcı, İ. 2007. Personal, Physical and Socioeconomic Factors Affecting Farmers' Adoption of Land Consolidation. Spanish Journal of Agricultural Research, 5(2): 204-213.

Akkaya, S. 2004. Arazî Toplulaştırmasının Toplu Yağmurlama Sistemlerinin Projelenmesine ve İşletilmesine Etkileri. Selçuk Üniversitesi Fen Bilimleri Enstitüsü Tarımsal Yapılar ve Sulama Anabilim Dalı, Doktora Tezi, Konya.

Akşit, S. 2013. Arazi Toplulaștırması Üzerine Çiftçi Algısı: Yeşildere Örneği (Denizli). The Journal of Academic Social Science Studies, 6 (3): 1-19.

Alkan, G. 2014. Türkiye'de Muhasebe Alanında Yapılan Lisansüstü Tez Çalışmaları Üzerine Bir Araştırma (1984-2012). Muhasebe ve Finansman Dergisi, 61: 41-52.

Altıntaş, G. 2006. Tokat İli Erbaa Ovasında Arazi Toplulaştırması Yapılmış Alanlardaki Tarım İşletmelerinin Ekonomik Analizi ve Optimum Üretim Planlarının Belirlenmesi Üzerine Bir Araştırma, GOPÜ Fen Bilimleri Enstitüsü Tarım Ekonomisi Anabilim Dalı, Doktora Tezi, Tokat.

Arslan, H., Tunca, E. 2013. Effect of Land Consolidation on the Performance of Irrigation Projects. Anadolu Tarım Bilimleri Dergisi, 28 (3): 126-133

Ayranc1, Y. 2000. Using the Parcel Transposition Ratio (Pyo) in the Evaluation of Land Consolidation Projects. Turkish Journal of Agriculture and Forestry, 24(6):745-749.

Banger, G., Şişman A. 2001. Kırsal Alan Düzenlemelerinde Yöneylem Araştırmas
Tekniklerinin Uygulanması. HKMO Dergisi, 87: 8298.

Bayramoğlu, Z., Oğuz C. 2004. Arazi Toplulaştırması Yapılmıș Tarım Alanlarında Girdi Tasarrufu Üzerine Bir Araştırma: Çumra Küçükköy Örneği. Selçuk Üniversitesi Ziraat Fakültesi Dergisi, 18(34): 46-50.

Bilgin, C. 2014. Trakya Bölgesindeki Uygulanan Arazi Toplulaştırmasının Çiftçiler Üzerindeki Etkinliğinin İrdelenmesi. NKÜ Fen Bilimleri Enstitüsü Biyosistem Mühendisliği Anabilim Dalı, Yüksek Lisans Tezi, Tekirdağ.

Boyraz, Z., Üstündağ, Ö. 2008. Kirsal Alanlarda Arazi Toplulaştırma Çalışmalarının Önemi. NWSA: Nature Sciences, 3 (3):563-578.

Boztoprak, T. 2010. Arazi Toplulaştırma Çalışmasının Kültürteknik Özelliklerinin Sürdürülebilir Arazi Yönetimi Açısından İrdelenmesi: Kayseri Örneği. KTÜ Fen Bilimleri Enstitüsü Harita Mühendisliği Anabilim Dalı, Yüksek Lisans Tezi, Trabzon.

Boztoprak, T. 2015. Tapu ve Kadastrodan Kaynaklanan Bazı Sorunların Arazi Toplulaştırma Projesi Kapsamında Çözümüne Yönelik Öneriler. Sigma Mühendislik ve Fen Bilimleri Dergisi, 33(2): 250259.

Boztoprak, T., Demir, O., Çoruhlu, Y.E. 2015a. Tarımsal Arazilerin Düzenlenmesinde Kamulaştırma ile Arazi Toplulaştırması Yöntemlerinin Karşılaştırılması. Sigma Mühendislik ve Fen Bilimleri Dergisi, (baskıda).

Boztoprak, T., Demir, O., Çoruhlu, Y.E., Nişanc1, R. 2015b. Arazi Toplulaştırmasının Tarımsal İşletmelere Etkilerinin Araştırılması. Selçuk Üniversitesi Mühendislik, Bilim ve Teknoloji Dergisi, 3(3):1-11.

Bursalı, O. 2007. Arazi Toplulaştırma Projesi Yapılan Bir Köyde Yeşil Alan ve Rekreasyonel Alan Planlaması (Malatya İli Yeşilyurt İlçesi Görgü Köyü Örneği). ÇÜ Fen Bilimleri Enstitüsü Peyzaj Mimarlığı Anabilim Dalı, Yüksek Lisans Tezi, Adana.

Celebi, M., Sağlam, C., Duran, A. 2015. The Potential Contribution of Land Consolidation to Prevent Wind Erosion in Turkey. Fresenius Environmental Bulletin, 24 (2): 429-437.

Çalışkan, A., Ünal, D., Ünal, H. B. 2005. Menemen Ovası Sulama Şebekesinin Arazi Toplulaştırması Öncesi ve Sonrası Durumunun Değerlendirilmesi. EÜ. Ziraat Fakültesi Dergisi, 42(2): 109-120.

Çay T., Çevik, H. 2009. Arazi Düzenleme Sonuçlarının Anketlerle Analizi. Selçuk Üniv. MühendislikMimarlık Fakültesi Dergisi, 24 (3): 11-18.

Çay, T., İşcan, F. 2011. Land Consolidation Software Algorithm for Agricultural Reform in Turkey. Asian Journal of Rural Development, 1 (1):70-86.

Çelebi, M. 2010. Toplulaştırmanın Karaman İlinde Sulama ve Diğer Tarımsal Faaliyetlerin Verimliliği Üzerinde Etkileri. Tarım Bilimleri Araştırma Dergisi 3 (2): 1-6. 
Çelik, Y. 2000. Şanlıurfa İli Harran Ovasında Arazi Toplulaştırması Yapılmış Alanlarda Sulu Tarım Yapan ve Yapmayan Tarım İşletmelerinin Optimum Üretim Planlarının Tespiti Üzerine Bir Araştırma. Ankara Üniversitesi Fen Bilimleri Enstitüsü Tarım Ekonomisi Anabilim Dalı, Doktora Tezi, Ankara.

Çevik, H. 2010. Arazi Düzenleme Sonuçlarının Anketlerle Analizi. Selçuk Üniversitesi Fen Bilimleri Enstitüsü Harita Mühendisliği Anabilim Dalı, Yüksek Lisans Tezi.

Çiçek, D., Kozak, N. 2012. Anatolia: Turizm Araştırmaları Dergisi'nde Yayımlanan Hakem Denetimli Makalelerin Bibliyometrik Profili. Türk Kütüphaneciliği, 26 (4): 734-756.

Demirtaş, E.I., Sarı M. Sönmez N.K., Altuntaş, S. 2003. Arazi Toplulaştırmasında Kullanılan Toprak Derecelendirme Çalışmalarına Yeni Bir Yaklaşım. Derim, 20 (1): 19-26.

Demirtaş, E.I., Sarı M., 2003. Arazi Toplulaştırması. Derim, 20 (1): 48-58.

Dengiz, O., Şişman, A., Gülser, C., Şişman, Y. 2014. Arazi Toplulaştırmasında Kullanılan Arazi Kalite Derecelendirme Yöntemine Alternatif Yaklaşım. Toprak Su Dergisi, 3 (1): 59-69.

Dinçbilek, B. 2012. Arazi Toplulaştırmasının Toplu Yağmurlama Sulamada Sistem Planlaması ve Maliyetine Etkisi. Ankara Üniversitesi Fen Bilimleri Enstitüsü Tarımsal Yapılar ve Sulama Anabilim Dalı, Doktora Tezi.

Doğru, M., Gençosman, T., Ataalkın, A. N., Şeker, F. 2012. Fen Bilimleri Eğitiminde Çalışılan Yüksek Lisans ve Doktora Tezlerinin Analizi. Türk Fen Eğitimi Dergisi, 9(1): 49-64.

Durukan, S., 2005. Çanakkale Bölgesinde Arazi Toplulaştırma Uygulamaları ve Kumkale Ovası Arazi Toplulaştırma Projesi. ÇOMÜ Fen Bilimleri Enstitüsü Tarımsal Yapılar ve Sulama Anabilim Dal1, Yüksek Lisans Tezi, Çanakkale.

Ekinci, K. 2010. Arazi Toplulaştırması Konusunda Çiftçi Davranıșlarının Belirlenmesi (Bafra Ovası Örneği). GOPÜ Fen Bilimleri Enstitüsü Tarım Ekonomisi Anabilim Dalı, Yüksek Lisans Tezi, Tokat.

Eminoğlu, G., Çakmak, B. 2013. Burdur-KemerElmacık Köyü Arazi Toplulaştırma Etkinliğinin Değerlendirilmesi. Gaziosmanpaşa Bilimsel Araştırma Dergisi, 5:39-53.

Erdoğan, A. 2000. Adana-Yüreğir Ovası Sulama Sahası Yemişli Köyü Arazi Toplulaştırması Sonunda Oluşacak Ortalama Parsel Büyüklüğünün Belirlenmesi. İTÜ Fen Bilimleri Enstitüsü Harita Mühendisliği Anabilim Dalı, Yüksek Lisans Tezi, İstanbul.

Eser, Ö. 2006. Gaziantep Nurdağı Gedikli Köyü Arazi Toplulaştırması Etkinliği. KSÜ Fen Bilimleri Enstitüsü Tarımsal Yapılar ve Sulama Anabilim Dalı, Yüksek Lisans Tezi, Kahramanmaraş.
Eser, Ö., Uçan, K. 2012. Arazi Toplulaştırılması Etkinliğinin Belirlenmesi. KSÜ Doğa Bilimleri Dergisi, 15(2): 38-45.

Göçmen, B. 2004. Arazi Toplulaştırmasının Kırsal Görünüm Planlaması ve Geliştirilmesindeki Yeri ve Bursa-Osmangazi-Doğanc1 Köyü Örneği. UÜ Fen Bilimleri Enstitüsü Tarımsal Yapılar ve Sulama Anabilim Dalı, Yüksek Lisans Tezi, Bursa.

Gun, S. 2003. Legal State of Land Consolidation in Turkey and Problems in Implementation. Pakistan Journal of Biological Sciences, 6 (15):1380-1383.

Gülçubuk, B., 2013.Türkiye Tarımının Ekonomi-Politik ve Sosyolojik Nitelikleri Açısından Arazi Toplulaştırması. Türk Tarım Dergisi, 210:16-21.

Güler, M. 2010. Simpson İndeksinin Toplulaştırma Çalıșmalarında Kullanılma Olanağı Üzerine Araştırma. Uludağ Üniversitesi Fen Bilimleri Enstitüsü Tarımsal Yapılar ve Sulama Anabilim Dalı, Yüksek Lisans Tezi.

Gündoğdu, K.S., Akkaya Aslan, Ş.T., Arıcı, İ. 2003. Arazi Toplulaştırmasında Parsel Değer Sayılarının Coğrafi Bilgi Sistemi Kullanılarak Belirlenmesi. Uludağ Üniversitesi Ziraat Fakültesi Dergisi, 17(1): $137-148$

Itır, O. 2013. Kayseri - Melikgazi - Sarımsaklı Köyü Arazi Toplulaştırma Projesi ve Toplulaştırma Sonrasında Yol - Parsel Durumlarının Analizi. Ankara Üniversitesi Fen Bilimleri Enstitüsü Tarımsal Yapılar ve Sulama Anabilim Dalı, Yüksek Lisans Tezi.

İnceyol, Y. 2000. Güneydoğu Anadolu Projeleri'nde (GAP) Yapılan Arazi Toplulaştırma Çalışmalarında Koordinasyon ve Planlama Sorunları. Selçuk Üniversitesi Fen Bilimleri Enstitüsü Harita Mühendisliği Anabilim Dalı, Yüksek Lisans Tezi.

İnceyol, Y. 2014. Arazi Düzenleme Çalışmalarında Genetik Algoritma Uygulaması. Selçuk Üniversitesi Fen Bilimleri Enstitüsü Harita Mühendisliği Anabilim Dalı, Doktora Tezi, Konya.

İnceyol, Y., Çay, T. 2001. Güneydoğu Anadolu Projeleri'nde (GAP) Yapılan Arazi Toplulaştırma Çalışmalarında Koordinasyon Sorunları. Selçuk Üniversitesi Mühendislik Mimarlık Fakültesi Dergisi, 16 (1): 34-40.

İşcan, F. 2003. Arazi Toplulaştırması Yazılımı İçin Algoritma Geliştirilmesi. Selçuk Üniversitesi Fen Bilimleri Enstitüsü Harita Mühendisliği Anabilim Dalı, Yüksek Lisans Tezi, Konya.

İşcan, F. 2009. Arazi Düzenleme Çalışmalarında Bulanık Mantık. Selçuk Üniversitesi Fen Bilimleri Enstitüsü Harita Mühendisliği Anabilim Dalı, Doktora Tezi.

İşcan, F. 2010. The Effects of Different Land Reallocation Models Applied in Land Consolidation Projects on Parcel Transposition: Example of Karatepe Village, Turkey. Scientific Research and Essays, 5 (9):873-882.

Kanlı U., Gülçiçek, Ç., Göksu, V., Önder, N., Oktay, Ö., Eraslan, F., Eryılmaz, Al., Güneş, B. 2014. 
Ulusal Fen Bilimleri ve Matematik Eğitimi Kongrelerindeki Fizik Eğitimi Çalışmalarının İçerik Analizi. Gazi Üniversitesi Eğitim Fakültesi Dergisi, 34(2): 127-153.

Kara, F. 2012. Arazi Toplulaştırma Çalışmalarında Yapay Zeka Uygulamalarının Kullanım Olanakları: Amasya İli Gümüşhacıköy İlçesi, Keçiköy Beldesi Uygulaması. OMÜ Fen Bilimleri Enstitüsü Tarımsal Yapılar ve Sulama Anabilim Dalı, Yüksek Lisans Tezi.

Keskin, B. 2014. Arazi Toplulaştırmasında İstek Öncelikli Otomatik Dağıtım Modelinin Performans Değerlendirmesi. Uludağ Üniversitesi Fen Bilimleri Enstitüsü Biyosistem Mühendisliği Anabilim Dalı, Yüksek Lisans Tezi.

Keskin, K. 2000. Türkiye'de Arazi Toplulaştırmasında Değer Biçme Uygulamaları. Tarım Ekonomisi Dergisi, 5(1):48-60.

Kır, M. 2012. Sinop Boyabat Cemalettin Köyü Arazi Toplulaştırmasının Tarımsal Altyapı Hizmetleri Yönünden Değerlendirilmesi. GOPÜ Fen Bilimleri Enstitüsü Tarım Ekonomisi Anabilim Dalı, Yüksek Lisans Tezi.

Kizılaslan, N., Almus S., 2000. Tokat-Zile-Güzelbeyli Beldesinde Uygulanan Arazi Toplulaştırmasında Benimsemeyi Etkileyen Sosyo-Ekonomik Faktörlerin Belirlenmesi Üzerine Bir Araştırma. Gaziosmanpaşa Üniversitesi Ziraat Fakültesi Dergisi, 17(1): 38-49.

Kızılok, N. 2009. Arazi Toplulaştırma Projelerinde Uydu Görüntü Verilerinin Kullanımı. Erciyes Üniversitesi Fen Bilimleri Enstitüsü Harita Mühendisliği Anabilim Dalı. Yüksek Lisans Tezi, Kayseri.

Kirmik1l, M., Arıc1, İ. 2013. The use of Landscape Metrics to Assess Parcel Conditions Pre-And PostLand Consolidation. Journal of Food, Agriculture \& Environment 11 (2): 985-989.

Kirmikıl, M., Arıc1, İ. 2014. Effects of Land Consolidation at Application of Irrigation Projects on Rural Area. Gaziosmanpaşa Üniversitesi Ziraat Fakültesi Dergisi, 31 (3):32-40.

Kirmikil, M. 2010. Sulama Proje Alanlarında Kırsal Alan Geliştirilmesi İçin Arazi Toplulaştırması Rolünün GIS Destekli Analizi. Uludağ Üniversitesi Fen Bilimleri Enstitüsü Tarımsal Yapılar ve Sulama Anabilim Dalı, Doktora Tezi.

Kozak, N. 2000. Türkiye'de Akademik Turizm Literatürünün Gelişim Süreci Üzerine Bir İnceleme. Doğu Akdeniz Üniversitesi Turizm Araştırmaları Dergisi, 1 (1):15-55.

Köse, T. 2009. Arazi Toplulaştırmasının Sulama Sistemlerine Etkisi (Manisa Salihli Sağ Sahil Sulama Alanı Örneği). Ankara Üniversitesi Fen Bilimleri Enstitüsü Tarımsal Yapılar ve Sulama Anabilim Dalı, Yüksek Lisans Tezi.

Köseoğlu, M. 2002. Arazi Toplulaştırma Planlama Çalışmalarında Uzaktan Algılama Tekniklerinden Yararlanma Olanakları. Uludağ Üniversitesi Fen
Bilimleri Enstitüsü Tarımsal Yapılar ve Sulama Anabilim Dalı, Yüksek Lisans Tezi.

Köseoğlu, M., Gündoğdu, K.S. 2004. Arazi Toplulaştırma Planlama Çalışmalarında Uzaktan Alg1lama Tekniklerinden Yararlanma Olanakları. Uludağ Üniversitesi Ziraat Fakültesi Dergisi, 18 (1): 45-56.

Kuşlu, Y. 2004. Kuzgun Barajı Sulama Alanında Arazi Toplulaştırma Potansiyelinin Belirlenmesi. Atatürk Üniversitesi Fen Bilimleri Enstitüsü Tarımsal Yapılar ve Sulama Anabilim Dal, Doktora Tezi.

Kuşlu, Y., Yağanoğlu, A. 2007. Kuzgun Barajı Sulama Alanında Yapısal Durumun Belirlenmesi. Atatürk Üniversitesi Ziraat Fakültesi Dergisi, 38 (1): 71-81.

Küsek G., Deveci H.V. 2013. Ülkemizde Arazi Toplulaştırması. Türk Tarım Dergisi, 210:30-37.

Küzeci, N. 2008. Avrupa Birliği Üyelik Sürecinde Türkiye'deki Arazi Toplulaştırma Çalışmaları. Atatürk Üniversitesi Fen Bilimleri Enstitüsü Tarımsal Yapılar ve Sulama Anabilim Dalı, Yüksek Lisans Tezi, Erzurum.

Manavbaş1, İ.D. 2012. Sivas İli Ulaş İlçesi Karacalar Köyü Arazi Toplulaştırma Çalışması ve Uygun Yağmurlama Sulama Sisteminin Projelenmesi. Ankara Üniversitesi Fen Bilimleri Enstitüsü Tarımsal Yapılar ve Sulama Anabilim Dalı, Yüksek Lisans Tezi, Ankara.

Oğuz, C., Bayramoğlu, Z. 2004. Konya İli Çumra İlçesinde Arazi Toplulaştırması Sonrası Farklı Parsel Genişliklerinin Birim Maliyetler Üzerine Etkisi; Küçükköy Örneği. Selçuk Üniversitesi Ziraat Fakültesi Dergisi, 18(34): 70-75.

Ormancı, M. 2015. Arazi Toplulaştırmasının Açık Kanal ve Yağmurlama Sulama Sistemlerinin Yatırım Maliyeti Üzerine Etkisinin Belirlenmesi: DenizliTavas-Kızılcabölük Örneği. ADÜ Fen Bilimleri Enstitüsü Tarımsal Yapılar ve Sulama Anabilim Dalı, Yüksek Lisans Tezi, Aydın.

Önal, A. 2004. Konya-Çumra-Abditolu Köyü Arazi Toplulaştırma Alanındaki Toprakların Değerlendirme Kriterlerindeki Değişikliklerin Belirlenmesi. Selçuk Üniversitesi Fen Bilimleri Enstitüsü Tarımsal Yapılar ve Sulama Anabilim Dalı, Yüksek Lisans Tezi, Konya.

Özer, A. 2010. Çanakkale İli Biga İlçesi Yeniçiflik Köyü Arazi Toplulaştırması Sonrası Durumun İzlenmesi ve Değerlendirilmesi. ÇOMÜ Fen Bilimleri Enstitüsü Tarımsal Yapılar ve Sulama Anabilim Dalı, Yüksek Lisans Tezi, Çanakkale.

Polat, H.E., Manavbaş1, İ.D. 2012. Arazi Toplulaştırmasının Kırsal Alanda Yakıt Tüketimi ve Karbondioksit Salınımına Etkisinin Belirlenmesi. Tarım Bilimleri Dergisi, 18:157-165.

Sayilan, H. 2014. Importance of Land Consolidation in the Sustainable Use of Turkey's Rural Land Resources. Procedia-Social and Behavioral Sciences, 120: 248-256.

Sert, A. 2005. Kamulaştırma Amaçlı Arazi Toplulaştırma. YTÜ Fen Bilimleri Enstitüsü Jeodezi 
ve Fotogrametri Mühendisliği Anabilim Dalı, Yüksek Lisans Tezi, İstanbul.

Sönmez, N.K., Sarı, M., Demirtaş, E.I., Altuntaş, S. 2005. Arazi Toplulaştırmasında Kullanılan Farklı Toprak Derecelendirme Yöntemlerinin Karşılaştırılması. Akdeniz Üniversitesi Ziraat Fakültesi Dergisi,18(3): 425-435.

Sönmezyıldız, E. 2012. Eskișehir Beyazaltın Köyü Arazi Toplulaştırma Alanında Sulama Performansının Değerlendirilmesi. Ankara Üniversitesi Fen Bilimleri Enstitüsü Tarımsal Yapılar ve Sulama Anabilim Dalı, Yüksek Lisans Tezi, Ankara.

Sönmezyıldız, E., Çakmak, B. 2013. Eskişehir Beyazaltın Köyü Arazi Toplulaştırma Alanında Sulama Performansının Değerlendirilmesi. Akdeniz Üniversitesi Ziraat Fakültesi Dergisi, 26 (1): 33-40.

Şahin, M. 2001. Çumra'daki Bazı Arazi Toplulaştırma Projelerinde Toprak Tuzluluğundan Kaynaklanan Arazi Değerlendirme Sorunları. Selçuk Üniversitesi Fen Bilimleri Enstitüsü Tarımsal Yapılar ve Sulama Anabilim Dalı, Yüksek Lisans Tezi, Konya.

Temel, M. 2013. Kirsal Alanların Korunarak Kalkınmasında ve Planlanmasında Bir Araç Olarak Arazi Toplulaştırması: Avrupa Birliği-Türkiye Karşılaştırması. Gazi Üniversitesi Fen Bilimleri Enstitüsü Şehir ve Bölge Planlama Anabilim Dalı, Yüksek Lisans Tezi, Ankara.

Temizel, K.,E., Ayranc1, Y., Okant, M. 2012. Blok ve Parsel Yönlendirmesinin Arazi Toplulaştırmasındaki Önemi. Anadolu Tarım Bilimleri Dergisi, 27(1): 1-5.

Tulukcu, E., Çağla, H. 2005. Çumra Tarımı ve Arazi Toplulaştırması. Selçuk Üniversitesi Teknik-Online Dergi, 4 (1): 1-19.

Turan, S., Karadağ, E., Bektaş, F., Yalçın, M. 2014. Türkiye'de Eğitim Yönetiminde Bilgi Üretimi: Kuram ve Uygulamada Eğitim Yönetimi Dergisi 2003-2013 Yayınlarının İncelenmesi. Kuram ve Uygulamada Eğitim Yönetimi, 20 (1): 93-119.

Tuşat, H. 2014. Arazi Toplulaştırma Çalışmalarında Kullanılan Harita Üretim Tekniklerinin Karşılaştırılması. Aksaray Üniversitesi Fen Bilimleri Enstitüsü Harita Mühendisliği Anabilim Dalı, Yüksek Lisans Tezi, Aksaray.

Uçar, D. 2002. Konya Çumra İlçesinin Köylerinde Arazi Toplulaştırmasının Tarımsal Altyapı Hizmetlerine Etkisi. Selçuk Üniversitesi Fen Bilimleri Enstitüsü Tarımsal Yapılar ve Sulama Anabilim Dalı, Yüksek Lisans Tezi, Konya.

Uçar, Y. 2001. Isparta-Atabey Sulamasında Su Dağıtım ve Kullanım Etkinliğine Arazi Toplulaștırmasının Etkisi. Selçuk Üniversitesi Fen Bilimleri Enstitüsü Tarımsal Yapılar ve Sulama Anabilim Dalı, Doktora Tezi, Konya.

Uçar, Y., Bölükmeşe, Ö., Çakmakcı, T. 2013. A Survey Study on Determination of Farmers'Opinions About the Land Consolidation Project Implemented in
Turkey: with Special Reference to Burdur Province. Scientific Papers-Series A, Agronomy 56:147-151.

Uçar, Y., Kara, M. 2006. Arazi Toplulaştırmasının Su İletim ve Dağıtım Performansına Etkisi. KSÜ Fen ve Mühendislik Dergisi, 9(1):117-124.

Uyan, M. 2011. Arazi Düzenlemesi Çalışmalarında Mekansal Karar Destek Sistemler Kurulumu ve Uygulaması. Selçuk Üniversitesi Fen Bilimleri Enstitüsü Harita Mühendisliği Anabilim Dalı, Doktora Tezi.

Uyan, M., Çay, T., Inceyol, Y., Haklı, H. 2015. Comparison of Designed Different Land Reallocation Models in Land Consolidation: A Case Study in Konya/Turkey. Computers and Electronics in Agriculture, 110: 249-258.

Uzun, Ö. 2002. Türkiye'deki Arazi Toplulaştırma Uygulamalarının, Devlet Yatırımları ve Çiftçi Gelirleri Üzerine Etkisinin Araştırılması ve Uygulamalarda Kullanılabilir Bir Model Oluşturulması. KSÜ Fen Bilimleri Enstitüsü Tarımsal Yapılar ve Sulama Anabilim Dalı, Yüksek Lisans Tezi, Kahramanmaraş.

Ünal Akyürek, G. 2014. Bursa Yenişehir Karaköy Karacaali ve Menteşe Köyleri Sınır Düzeltmesi Ve Köyler Arası Taşıma Yapılarak Hazırlanan Arazi Toplulaştırma Projesi Üzerine Bir Çalışma. Trakya Üniversitesi Fen Bilimleri Enstitüsü Tarımsal Yapılar ve Sulama Anabilim Dalı, Yüksek Lisans Tezi, Tekirdağ.

Ünal, A.D. 2003. Menemen Ovası Sulama Şebekesinin Toplulaştırma Öncesi ve Sonrası Durumunun Değerlendirilmesi Üzerine Bir Araştırma. Ege Üniversitesi Fen Bilimleri Enstitüsü Tarımsal Yapılar ve Sulama Anabilim Dalı, Yüksek Lisans Tezi, İzmir.

Ünal, G. 2001. Bursa Yenișehir Karaköy Karacaali ve Menteşe Köyleri Sınır Düzeltmesi ve Köyler Arası Taşıma Yapılarak Hazırlanan Arazi Toplulaştırma Projesi. Trakya Üniversitesi Fen Bilimleri Enstitüsü Tarımsal Yapılar ve Sulama Anabilim Dalı, Yüksek Lisans Tezi, Tekirdağ.

Yalçın, G. 2011. Legal Infrastructure of Agricultural Areas in the View of Cadastre and Ownership in Turkey and Sustainable Development. African Journal of Agricultural Research, 6 (33): 6750-6754.

Yaldır, A.K., Rehman T. 2002. A Methodology for Constructing Multicriteria Decision Support Systems for Agricultural Land Consolidation Using GIS and API: An Illustration From Turkey, Computers and Electronics in Agriculture, 36 (1):5578.

Yilmaz, N. 2001. Konya Ovası'nda Uygulanan Bir Kapalı Drenaj Sahasında Proje Performansının Belirlenmesi ve Drenajın Toplulaştırmada Arazi Değerlendirilmesine Etkisi. Selçuk Üniversitesi Fen Bilimleri Enstitüsü Tarımsal Yapılar ve Sulama Anabilim Dalı, Yüksek Lisans Tezi. 